\title{
Hemoperitoneo por linfoma em raiz mesentérica
}

Maria Eduarda Moreira Volpato, Paulo Henrique dos Santos Castro, Aline Matos Curvelo Barros, Sofia Cicolo Silva, Luciana

Neves Torres, Julio David Spagnolo, Carla Bargi Belli"

Faculdade de Medicina Veterinária e Zootecnia, Universidade de São Paulo (USP), São Paulo, SP, Brasil

*Autor correspondente

e-mail: cbbelli@usp.br

\section{Resumo}

Hemoperitoneo é o acúmulo anormal de sangue na cavidade peritoneal. Embora a real frequência do mesmo em equinos seja desconhecida, esta condição tem sido pouco relatada nesta espécie. A ampla possibilidade de causas e a severidade das manifestações presentes requerem uma interpretação cuidadosa dos achados hematológicos e bioquímicos e dos resultados de procedimentos como abdominocentese e ultrassom abdominal. A ocorrência de hemoperitoneo pode ser secundária à ruptura esplênica ou hepática, ruptura de artérias mesentéricas por migração larval, ruptura de artéria uterina durante o parto, coagulopatias e lesões neoplásicas ou abscessos. Dentre as neoplasias abdominais relatadas em equinos está presente o linfoma, que é determinado por transformações malignas das células linfoides, podendo ser considerado a forma neoplásica mais comum do sistema hemolinfático nos equinos. Pode ser classificado como multicêntrico, alimentar, esplênico, cutâneo e subcutâneo. As manifestações clínicas nos cavalos com linfoma não são específicas e variam muito dependendo dos órgãos afetados. Algumas manifestações comuns incluem perda de peso, letargia, linfadenopatia e edema. Os achados laboratoriais incluem anemia, hiperfibrinogenemia, hiperproteinemia, hiperglobulinemia e hipoalbuminemia. Relata-se aqui o caso de um equino encaminhado ao HOVET-USP, Quarto de Milha, macho, de cerca de 6 anos, com queixa de edema recorrente em bolsa escrotal, associado à distensão abdominal e alterações em auscultação pulmonar. 0 veterinário que encaminhou o animal, durante exame ultrassonográfico, encontrou grande presença de líquido livre na cavidade com características de heterogeneidade que, após abdominocentese, verificouse ser sanguinolento. No HOVET-USP, o exame físico revelou baixo escore corporal, taquicardia, mucosas congestas, auscultação pulmonar com reverberação de ruídos cardíacos e intestinais e distensão abdominal. No hemograma havia neutrófilos hipersegmentados, aumento de monócitos $(1.068 / \mu \mathrm{L})$ e de fibrinogênio $(600 \mathrm{mg} / \mathrm{dL})$. Também havia diminuição de albumina $(1,82 \mathrm{~g} / \mathrm{dL})$ e aumento de bilirrubina indireta $(6,47$ 
$\mathrm{mg} / \mathrm{dL})$. No perfil renal, observou-se aumento de ureia $(73,7 \mathrm{mg} / \mathrm{dL})$. Realizou-se abdominocentese, onde foi observado líquido peritoneal de aspecto sanguinolento, com $5 \%$ de hematócrito, proteína $2 \mathrm{~g} /$ dL, 24.900 de contagem de células nucleadas e lactato $18,6 \mathrm{mmol} / \mathrm{L}$. No ultrassom abdominal, notou-se grande quantidade de líquido com presença de fibrina, baço com superfície irregular, de tamanho reduzido e afastado da parede abdominal, alças intestinais com pouca quantidade de conteúdo alimentar. Diante das alterações observadas, indicou-se uma laparotomia exploratória. Durante o procedimento cirúrgico, ao realizar a incisão na linha média abdominal, ocorreu drenagem de grande quantidade de líquido sanguinolento. Na exploração da cavidade abdominal, observou-se a presença de formação tumoral em porção distal do jejuno, estendendo-se desde a raiz mesentérica até a junção do mesentério com a alça intestinal. Devido à extensão da formação e à impossibilidade de remoção cirúrgica, associado ao grande sangramento, indicou-se a eutanásia do animal. Durante a necropsia, além da tumoração evidenciada na laparotomia, havia também aumento de linfonodos mediastinais. Foi colhido material para histopatológico, onde foi diagnosticado linfoma. Este equino apresentou a forma multicêntrica do linfoma. 0 incomum do caso é o acometimento da raiz mesentérica e o desenvolvimento de distensão abdominal e hemoperitoneo, o que é pouco relatado na literatura. 0 diagnóstico definitivo com o animal vivo é difícil, porém neste caso foi possível devido à laparotomia exploratória. Conclui-se que o linfoma deve ser considerado como diagnóstico diferencial em cavalos com hemoperitoneo.

Palavras-chave: Hemoperitoneo. Linfoma. Equino. 